\title{
Signo ideológico e enunciado na construção e disseminação de fake news: uma possibilidade de análise do fenômeno sob o viés bakhtiniano
}

\author{
Ideological sign and enunciation in the construction and dissemination of fake news: a \\ possibility of analysis of the phenomenon under the bakhtinian view
}

\author{
Jonathan Bernardo Menger ${ }^{1}$ \\ Pontifícia Universidade Católica do Rio Grande do Sul \\ menger.jb@gmail.com
}

\begin{abstract}
RESUMO: O presente artigo objetiva refletir sobre as fake news e suas consequências na sociedade, por meio de algumas noções da Análise do Discurso bakhtiniana, como ideologia, signo e enunciação. Buscando elucidar de que maneira tais conceitos-chave podem ser aproveitados para uma análise desse fenômeno, utiliza-se uma informação deflagrada como falsa pelo grupo de checagem "Fato ou Fake", no Facebook, e os respectivos comentários à postagem. Assim, pode-se concluir que a reflexão sobre questões dialógicas contribui valiosamente para o estudo e a análise das fake news, que, assim como a linguagem, é um fenômeno puramente social. Além disso, acredita-se que as discussões sobre esse assunto possam favorecer a ampliação científica sobre essa realidade, a qual tem sido pouco discutida em artigos acadêmicos, sobretudo em estudos (trans)linguísticos.
\end{abstract}

Palavras-chave: Análise do discurso; Bakhtin; Signo; Enunciação; Fake news.

ABSTRACT: This article aims to dwell on fake new sand its consequences in society, through some notions of Bakhtinian Discourse Analysis, such as ideology, sign and enunciation. In order to clarify how these key concepts can be harnessed for an analysis of this phenomenon, I utilized information exposed as false by the fact-checking organization known as "Fato ou Fake" at Facebook and its comments published by its followers. Thus, it can be concluded that reflection upon dialogical questions contributes valuable to the study and analysis of fake news, which, like language, is a purely social phenomenon. Moreover, it is believed that discussions on this subject may favor the scientific expansion on this reality, which has been little discussed in academic articles, especially in (trans) linguistic studies.

Keywords: Discourse analysis. Bakhtin. Sign. Enunciation. Fake news.

\footnotetext{
${ }^{1}$ Mestrando em Letras/Linguística. Bolsista CAPES.
} 


\section{Considerações iniciais}

Pensando-se que não há realização comunicativa sem interação interdiscursiva, é importante dar créditos a Mikhail Bakhtin no trabalho com a temática em questão, em vista de sua preocupação em observar o fenômeno da língua in actu, como estando sempre apoiada sobre as relações sociais, visto que a linguagem se compõe de várias tonalidades, tornando-se heterogênea, incessante e inacabada na vida cotidiana. $\mathrm{O}$ discurso nasce das necessidades de aproximação e compreensão intersubjetiva. Dessa forma, toma-se como ponto de partida para a análise das fake news - fato puramente social, político e dialógico - a linguagem, alicerçada em algumas noções desenvolvidas nos trabalhos do Círculo, a saber: "ideologia", "significação sígnica" e "enunciação"; extraídas dos textos Marxismo e filosofia da linguagem; A construção da enunciação e outros ensaios; Discurso na vida e Discurso na arte: sobre poética sociológica e de outras, discutidas no conjunto de suas obras. Além disso, abordar-se-á também a contribuição de alguns autores que estudam as notícias falsas, a fim de proporcionar uma reflexão geral sobre o fenômeno, entrelaçando-o a um viés filosófico do discurso.

Sendo assim, no primeiro momento, procura-se expor brevemente o contexto em que se inserem as fake news, argumentando sobre suas causas, consequências e sobre alguns pontos de sua formação histórica. No segundo momento, pretende-se observar os conceitoschave, mencionados acima, na perspectiva dialógica do discurso. Sabendo que essas noções não são estanques, serão realizadas, tanto no decorrer da rápida explanação quanto no da investigação proposta, inferências a outros aspectos discursivos desenvolvidos pelo Círculo, de forma a tornar mais heterogêneo o compilado de informações abordadas neste trabalho. Por último, no terceiro momento, busca-se realizar a análise de uma fake news em uma possível abordagem bakhtiniana, de maneira a acrescentar uma visão crítica sobre esse fenômeno, bastante presente e atual.

\section{Uma breve explanação contextual do fenômeno fake news}

As fake news, termo comumente conhecido em português por "notícias falsas", designam-se por informações que se travestem da verdade com o objetivo de enganar os entes sociais participantes das diversas esferas de manifestações discursivas. Sem o compromisso 
Jonathan Bernardo Menger. Signo ideológico e enunciado na construção e disseminação de fake news: uma possibilidade de análise do fenômeno sob o viés bakhtiniano.

com a realidade objetiva dos fatos, elas têm sido vistas na mídia com uma valoração ${ }^{2}$ negativa, pois, segundo Gabriel (2018), elas “[...] geram percepções equivocadas e perigosas que tendem a comprometer a saúde social (GABRIEL, 2018, p. 9) ${ }^{3}$.

As fake news não apresentam compromisso com a verdade em suas veiculações discursivas, e por isso podem gerar "desinformações". Carvalho e Matheus (2018) analisam as produções científicas sobre esse tema para a área da ciência da informação, trazendo uma importante observação ao atestarem que as notícias falsas e a desinformação, embora andem juntas, são diferentes. Primeiro, porque as fake news objetivam informar, mas ao mesmo tempo desinformam o seu público, em virtude de não lhe trazer a realidade clara e objetiva dos fatos. Segundo, porque a desinformação - que também é enganosa - não deixa de ser uma informação. A desinformação é tida, nesse aspecto, como a resposta frente à determinada mentira contada, isto é, a forma como o público reage perante uma notícia enganosa ${ }^{4}$. Dessa forma, é possível constatar que tanto fake news quanto desinformação são termos indissociáveis, construídos em discursos simultâneos. O interessante de se ressaltar nessa duplicidade é que o indivíduo social, que compartilha falsas notícias com os demais, não tem necessariamente o objetivo de levar uma desinformação adquirida adiante, como uma espécie de enganação, pois muitas vezes não tem clareza sobre a fonte do material recebido. Ingenuamente, então, incorre ao erro, e não à mentira, por desconhecer o discurso a ele disseminado.

As fake news sempre existiram, e é difícil precisar suas primeiras ocorrências. No entanto, ao se considerar as palavras de Volochínov (2013), sobre o fato da interação interdiscursiva se fazer de um intercâmbio verbal estabelecido entre os entes do discurso, pode-se pressupor que elas tenham raízes desde as primeiras interações orais entre os agentes interdiscursivos. Harari (2017), por exemplo, explica que as falsas informações têm origem desde os primatas no período da Pré-História. Os ancestrais necessitavam criar elos uns com os outros para interagir e se comunicar e, à medida que sua comunidade crescia, precisavam de liderança para comandar seus grupos, os quais acabavam apresentando conflitos internos devido à falta de organização. Dessa forma, era preciso repassar histórias entre eles, que alimentassem seu imaginário. Segundo o autor, na Revolução Cognitiva, a fofoca foi uma maneira de contribuir para grupos mais estáveis, com menos conflitos, pois precisavam caçar e lutar juntos para criarem certa harmonia em sua convivência. Harari questiona:

\footnotetext{
${ }^{2}$ A noção de "valor" será desenvolvida na seção 3.

${ }^{3}$ Citação extraída do prefácio de Como sair das bolhas, de Pollyana Ferrari (2018). Essa obra, que será citada em alguns momentos do texto, encontra-se nas referências deste artigo.

${ }^{4}$ Essa forma de reação será brevemente comentada ainda nesta seção, pelo termo "pós-verdade".
} 
Como o homo sapiens conseguiu ultrapassar esse limite crítico, fundando cidades com dezenas de milhares de habitantes e impérios que governam centenas de milhões? O segredo foi provavelmente o surgimento da ficção. Um grande número de estranhos pode cooperar de maneira eficaz se acreditar nos mesmos mitos (HARARI, 2017, p. 35).

Podem-se encontrar reflexos dessa espécie de intercâmbio social no fenômeno atual das fake news, no sentido de a mentira - os "mitos" - servir de instrumento para a criação e manipulação de grupos ideológicos, de forma a suprir desejos pessoais de quem dissemina uma informação enganosa e de forma a organizar certos grupos que compartilhem das mesmas ideologias. A crença numa ficção, nesse sentido, orienta os seres sociais a determinados pontos de vistas, independente da veracidade dos fatos.

Atualmente, as fake news ${ }^{5}$ têm repercutido bastante na mídia em geral, e muito disso se deve ao ano de 2016 com as eleições de Donald Trump, nos Estados Unidos, e também com o Brexit, com a saída do Reino Unido da União Europeia. Para D'Ancona (2018), tais impactos "[...] marcaram indubitavelmente um levante contra a ordem estabelecida" (D’ANCONA, 2018, p. 21).

As falsas informações se apoiam bastante em discursos que discorrem sobre políticas governamentais. No Brasil, por exemplo, o termo fake news apareceu de forma impactante nos meios de comunicação, durante as eleições de 2018. As notícias sobre política emergiram de tal forma que levaram as pessoas a serem manipuladas por outras devido à facilidade e à instantaneidade de acesso à informação, como no caso das plataformas virtuais. Isso fez com que se criassem eventos desagradáveis, provindos de interações não só virtuais, mas também reais, carregadas de discursos de ódio, de assédio, de ignorância e prepotência, num embate entre os que acreditavam ser verdadeira uma informação mentirosa com aqueles que refutavam a informatividade falsa a qualquer custo. A população estava descrente das propostas políticas, seguidas por anos afinco, sem chances de melhorias à realidade do país, que se encontrava em crise social, política e econômica. Esse cenário foi conveniente para as promessas do atual presidente brasileiro, e coincidem com as adotadas por Trump, em 2016. Como recorda D’Ancona (2018), o líder estadunidense objetivava igualmente acalentar os sentimentos dos cidadãos, os quais desejavam e buscavam fortemente por mudanças radicais:

\footnotetext{
${ }^{5} \mathrm{O}$ termo fake news já apareceu em outros momentos, mas com pouca notoriedade. De acordo com Vilela (2019), até o século XIX, o que se utilizava, nos países de língua inglesa, para denominar boatos enganosos era "false news". De outra mão, Claire Fallon, em matéria para o jornal americano Huffpost (2017), diz que o termo já foi citado em 1891, pelo The Buffalo Commercial. Esses textos estarão listados nas referências.
} 
Jonathan Bernardo Menger. Signo ideológico e enunciado na construção e disseminação de fake news: uma possibilidade de análise do fenômeno sob o viés bakhtiniano.

Esse foi o ponto: oferecer à grande massa de eleitores brancos uma série de inimigos contra quem eles poderiam se unir, uma história na qual seriam capazes de desempenhar um papel e um plano mítico de "Tornar a América Novamente Grande". O efeito foi narcótico, em vez de racional: melhor uma narrativa fantasiosa que parecia boa do que nenhuma. No centro dessa narrativa, estava o próprio Trump [...], bastante ridicularizado pela mídia - era exatamente o que tornava a história tão sedutora (D’ANCONA, 2018, p. 26).

O grande problema das falsas informações é que elas, inevitavelmente, culminam em discursos posteriores de "pós-verdade" . Conforme as palavras de D'Ancona (2018), esse conceito é pouco popular e recente, citado pela primeira vez nos anos 1990, designado como o processo sobre o qual convicções pessoais passam a ter mais importância do que os próprios fatos. Isso acarreta em desarmonia social no ato interlocutório, uma vez que a posse desses discursos causa para si e para os demais participantes problemas maiores, atingindo a sociedade em nível mais amplo. O autor analisa esse fenômeno como uma resposta do público às fake news, pois acredita que justamente as crenças de pós-verdade acontecem por meio da mentira antecedente, já que, quando ela se "reinvindica ser uma fonte, fica infinitamente mais difícil distinguir entre fato e mentira. Todos e ninguém são 'especialistas' (D'ANCONA, 2018, p. 59).

Nessa perspectiva, pode-se trazer também os argumentos de Ferrari (2018). Além de fazer considerações sobre o conceito de pós-verdade e suas consequências na vida cotidiana, ela explica que todos os seres sociais, por compartilharem de ideologias semelhantes, acabam por se situar envoltos numa espécie de bolha social, nas quais podem se cristalizar tanto a mentira como a verdade. A princípio, todos os indivíduos convivem entre si em bolhas ideológicas, mas há aqueles que distorcem os fatos, corrompendo com a ética e com a moral. Nisso, se dá a proposta de seu livro, levando seus leitores a refletirem sobre o quão se faz importante desvincular-se das falsas informações e apreciar uma visão mais crítica e reflexiva das situações que os acercam. Para a autora, a fuga desses grupos se faz importante num cenário com as fake news e pós-verdade, pois esses dois fenômenos “geram 'bolhas' de percepções equivocadas e perigosas que tendem a comprometer a saúde social (tanto individual quanto coletiva), só podendo ser combatidas por meio da educação, do pensamento crítico e da ética" (FERRARI, 2018, p. 74).

Em se tratando dos riscos à sociedade, o problema da pós-verdade, como consequência direta das fake news, pode ser recordado pelo movimento antivacina. Por tempos, acreditou-se - e ainda se acredita - que a vacina pode vir a ser prejudicial ao ser humano. Criou-se, por

\footnotetext{
${ }^{6}$ Segundo o site Carta Capital (2017), esse termo foi eleito palavra do ano em 2016, pelos Dicionários Oxford, pois teve um crescimento de $2000 \%$ nas buscas. O texto estará contemplado nas referências.
} 
Jonathan Bernardo Menger. Signo ideológico e enunciado na construção e disseminação de fake news: uma possibilidade de análise do fenômeno sob o viés bakhtiniano.

conseguinte, uma ideologia provinda de uma falsa crença, de que ela não faz bem. Isso é totalmente negativo para as relações interpessoais, principalmente no tangente à área da saúde, e se contrapõe diretamente ao discurso de estudiosos, os quais asseguram a importância de prevenções por meio de remediação. D’Ancona (2018, p. 68) relembra sobre essa situação, e alerta que "o recuo em relação à ciência se torna perigoso quando ameaça a saúde pública ou a segurança dos outros".

Retomando a pesquisa de Carvalho e Matheus (2018), além de analisarem as fake news e suas consequências no contexto digital, chamam atenção para o fato de haver pouca produção sobre o tema em trabalhos científicos. Nesse sentido, urge a necessidade de se construir conhecimentos e reflexões no combate a essa problemática atual.

\section{Noções de signo ideológico e enunciação para o círculo}

O Círculo de Bakhtin observa todas e quaisquer atividades humanas vistas de maneira coletiva, isto é, interindividual e, por isso, interativa. Além disso, se os seres sociais convivem entre si em sociedade, só os fazem por meio da linguagem, fenômeno que lhes proporciona essa interação, sempre incessante. A língua, tida no seu surgimento como "elemento de um processo de trabalho, estava ligada a necessidades econômicas e representava o resultado da organização produtiva da sociedade" (VOLOCHÍNOV, 2013, p. 137), já não pode ser mais vista como o autor a concebeu, uma vez que o próprio Círculo a enxerga como uma inevitável e incessante mudança. Nessa ideia de língua como movimento interdiscursivo, é possível observar questões de pós-verdade e fake news como fenômenos sociais nas interações humanas, uma vez que estão presentes na sociedade. Sendo assim, não poderia ocorrer, então, uma análise desse fenômeno e de suas consequências se não fosse pela linguagem, em razão de, para Volochínov ${ }^{7}$ (2013), a língua ser produto diretamente associado à atividade humana.

A palavra é o material linguístico-ideológico que guia as relações entre os agentes discursivos numa sociedade. Nas palavras do Círculo, os discursos são produzidos em forma de enunciados e, nesse sentido, torna-se indispensável falar na ideia de signo bakhtiniano. Para Volóchinov (2018, p. 93), "além dos fenômenos da natureza, dos objetos tecnológicos e dos produtos de consumo, existe um mundo particular: o mundo dos signos". Para o autor, o

\footnotetext{
${ }^{7}$ Os nomes, no decorrer do texto, estarão escritos diferentemente (como "Voloch[Í]nov / Vol[Ó]chinov / Volo[SH]inov"), devido ao fato de a autoria estar grafada de maneira distinta nas obras referenciadas neste artigo.
} 
signo nada mais é que uma entidade de significação que ultrapassa a existência de tal realidade. Volóchinov comenta que, por si só, um instrumento da natureza não é um signo. Utiliza como exemplo, em dada parte de seu texto, a foice e o martelo, cada qual com sua presença no mundo, sua objetividade particular, não podendo representar nada mais além de si mesmos; no entanto, ao serem utilizados juntos, apresentam caráter de signo, pois podem exprimir um sentido como um todo para além de sua existência. Volochínov (2013) explicita bem esse pensamento:

Os objetos da vida cotidiana [...] não têm nenhum significado ideológico. Nós podemos usá-los, examiná-los, estudar sua construção, especificar perfeitamente tanto o processo de sua preparação quanto sua destinação produtiva, mas, ainda que o desejássemos, não reteríamos dele mais que o próprio objeto [...] diferentemente dos signos (VOLOCHÍNOV, 2013, p. 191).

Portanto, segundo o que prediz o Círculo, deve-se avaliar o signo como "um fenômeno da realidade objetiva que se tornou fenômeno da realidade ideológica: o objeto se transformou em signo" (ibid., p. 192). No caso da palavra, que não é um objeto da natureza, Volochínov (2013) explicita que ela é um fenômeno ideológico por excelência, pois, em todo ato comunicativo, os seres sociais têm a necessidade de utilizá-la para referir a algo no universo. Pode-se pensar, no que tange às fake news, que determinados fatos da realidade objetiva só são refletidos em forma de "notícias"8 falsas porque são refratados por certas ideologias, as quais procuram sempre ir ao encontro de outras, formando grupos ideológicos - ou "bolhas", como designa Ferrari (2018) - que compartilhem de semelhantes visões de mundo. Elas se estabelecem, então, numa relação sígnica, pois são refratadas e refletidas na disseminação de uma mentira.

Volóchinov (2018, p. 93) retoma que “o campo ideológico coincide com o campo do signo", compreendendo a ideia de ideologia como fator importante na caracterização do signo em sua teoria. Para ele, "tudo o que é ideológico possui significação sígnica" (VOLOCHÍNOV, 2008, p. 93), ou seja, tudo o que tem valor no universo se torna um signo, pois é capaz de fazer referência a algo para além de si mesmo. Desse modo, a ideologia bakhtiniana se caracteriza pela interpretação e pela reflexão realizada por cada consciência social sobre tudo que lhe cerca. Então, entende-se por ideologia "todo o conjunto de reflexos e interpretações da realidade social e natural que se sucedem no cérebro do homem, fixados por

\footnotetext{
${ }^{8}$ Nem todas as fake news configuram o mesmo estilo e propósito de uma notícia. Por isso, o termo aparecerá, em alguns momentos, grafado entre aspas.
} 
Jonathan Bernardo Menger. Signo ideológico e enunciado na construção e disseminação de fake news: uma possibilidade de análise do fenômeno sob o viés bakhtiniano.

meio de palavras, desenhos, esquemas ou outras formas sígnicas" (VOLOCHÍNOV, 2013, p. 138).

Os termos "refração" e "reflexão" ilustram bem a noção de ideologia adotada pelo Círculo e são capazes de explicar suas estreitas relações com o signo discursivo de Bakhtin. O signo "reflete" e "refrata"; isto é, ele é o material da linguagem concretizado por meio daquilo que se pode absorver de determinado dado externo e, respectivamente, do que se pode reconstruir como seu reflexo. Logo,

O signo não é somente uma parte da realidade, mas também reflete e refrata uma outra realidade, sendo por isso mesmo capaz de distorcê-la, ser-lhe fiel, percebê-la de um ponto de vista específico e assim por diante. As categorias de avaliação ideológica (falso, verdadeiro, correto, justo, bom etc.) podem ser aplicadas a qualquer signo (VOLÓCHINOV, 2018, p. 93, grifo meu).

As ideologias também ganham vozes na sociedade a partir de quando aquele que recebe a informação deixa-se comover pelo discurso do outro com o qual construiu pontos de vistas afins, já que todo princípio do discurso contém, segundo Miotello (2016), um lugar valorativo, de posição verdadeira ou falsa. Por signo ideológico, Bakhtin (2018, p. 10) o considera "um reflexo das estruturas sociais; assim, toda modificação da ideologia encadeia uma modificação da língua”.

O autor acentua, portanto, que a língua é discurso e só tem sentido por si só porque é representativa e simbólica em uma determinada situação. Volochínov (2013, p. 144) aposta na linguagem como estando diretamente ligada às condições humanas, visto que ela "coopera involuntariamente para criar os embriões da divisão de classes [sociais] e de patrimônios da sociedade"

Portanto, a ideologia, como parte integrante do signo bakhtiniano, não irá jamais acontecer de forma isolada. Bakhtin e seu Círculo acreditam que, se há significação sígnica, há interação interdiscursiva. Sendo assim, "o signo surge apenas no processo de interação entre consciências individuais" (VOLÓCHINOV, 2018, p. 95). Embora o autor discuta que a consciência individualista seja sempre coletiva, embasado nos preceitos do psicologismo social, acredita ser importante fazer a distinção entre o ser coletivo e o ser individual. Para ele,

É preciso sempre distinguir rigorosamente o conceito de indivíduo como ser da natureza, tomado fora do mundo social, assim como ele é estudado e conhecido pelos biólogos, e o conceito de individualidade, que, construído sobre o indivíduo natural, é por sua vez uma superestrutura ideológica e sígnica, e portanto social (VOLÓCHINOV, 2018, p. 129). 
É importante observar também, na discussão sobre significação sígnica, a ideia de valoração, como correspondente à noção de "valor". Ao utilizarem de palavras para fazer referência a quaisquer coisas externas, os indivíduos sociais sempre as valoram, ou seja, atribuem-lhes valores. Frente a isso, pode-se dizer que cada tom valorativo está diretamente imbricado no construto ideológico de suas consciências individuais. Para Bakhtin (2018), a valoração tem a ver com o termo "axiologia", designa os tons atribuídos por cada indivíduo a seus enunciados para valorar determinada referência. Nesse sentido, é possível compreender que o tom axiológico, ou seja, a valoração, estabelece notórias congruências com os termos "ideologia" e "signo", pois eles ganham vida nos enunciados, concretizando-se na dialogia incessante das diversas camadas sociais. A expressão "fake news" recebe comumente valoração negativa, em vista de sua repercussão nos veículos de informação, e isso não é indevido, em se considerando suas consequências para a sociedade, a política e a economia. Ao referir-se às falsas informações, normalmente a elas é atribuída uma conotação obscura. No entanto, isso ocorre igualmente em lado oposto, pois a veracidade também passa a ganhar valorações sem teor positivo, mesmo havendo agências de checagem ${ }^{9}$ que realizam trabalhos sérios acerca do tema. Exemplo disso são as reações de pessoas que dizem ser falsa uma informação até mesmo quando ela é verdadeira.

Se a palavra é, por excelência, uma espécie de signo, pois é capaz de referir a algo além dela mesma, é através da enunciação que ela poderá ser articulada de forma a concretizar-se em discurso. A concepção de enunciado, logo, é encadeada a outros elementos discutidos pelo Círculo, como, por exemplo, a ideologia, o signo, o discurso.

Conforme aponta Brait e Melo (2017, p. 65), o conceito de enunciado, enunciado concreto ou enunciação - as autoras enxergam tais termos como sinônimos - aparecerá no conjunto das obras do filósofo russo e, por isso, não tem um conceito fechado e acabado em si. Ainda de acordo com as autoras,

A concepção de enunciado/enunciação não se encontra pronta e acabada numa determinada obra, num determinado texto: o sentido e as particularidades vão sendo construídos ao longo do conjunto das obras, indissocialvemente implicados em outras noções também paulatinamente construídas (p. 65)

No texto Discurso na vida e discurso na arte: sobre poética sociológica (1926), Voloshinov e seu Círculo abordam de que maneira o discurso se constitui na vida e na arte.

\footnotetext{
${ }^{9}$ Há empresas de fact-checking que procuram combater esse fenômeno. No Brasil, por exemplo, as agências Lupa e Aos Fatos têm sido reconhecidas pelo seu empenho no combate às fake news.
} 
Para isso, comentam que o enunciado, por ser um fenômeno dialógico, é inevitável entre os seres sociais, no processo de interação. Além disso, o autor considera não só a palavra como importante no processo de construção da enunciação, mas também seu evento exterior. $\mathrm{O}$ discurso só tem valor como um todo se se considerar em conjunto o sistema linguístico (o aspecto verbal) e o evento discursivo (o aspecto extraverbal). Dessa forma, para esclarecer o propósito de sua visão frente à concepção de enunciado, disserta suas ideias a partir do questionamento realizado logo no início do texto: "Como o discurso verbal na vida se relaciona com a situação extraverbal que o engendra?” (VOLOSHINOV, 1976, p. 6). Isso esclarece que apenas a observação da língua pela língua, ou seja, sua consideração como sistema imóvel de formas idênticas, não é capaz de esclarecer de maneira ampla e heterogênea o fenômeno da linguagem como um todo. No encontro com uma "notícia" falsa, seria impossível, por exemplo, uma apreciação da língua somente como forma, pois muitas vezes uma fake news como um enunciado completo, no sentido bakhtiniano, perpassa o código, exigindo uma leitura de outros elementos extralinguísticos (como é o caso de imagens, cores, formas, etc.), além de uma compreensão do material subentendido. Um exemplo disso poderá ser constatado na seguinte possibilidade de análise abaixo.

\section{Uma possibilidade de análise sob o viés bakhtiniano}

Nesta seção, objetiva-se investigar abordagens bakhtinianas anteriormente citadas, como signo ideológico, valor e enunciação, em materiais virtuais que se classificam como fake news. No decorrer da análise, inevitavelmente, serão realizadas relações com outras noções, porquanto a teoria do Círculo é abrangente e os aspectos trabalhados estão entrecruzados entre si. Entretanto, não é pretensão esgotar os diversos caminhos possíveis na análise do objeto

A coleta do material para análise foi realizada na página "Fato ou Fake", do Facebook, um serviço de checagem de fatos prestado pela Rede Globo desde 2018. Além da representação das falsas informações, serão utilizados também, como complemento de apoio ao que se deseja elucidar na breve pesquisa, os respectivos comentários de usuários virtuais à postagem apresentada. Mesmo o conteúdo sendo público e utilizá-los não denigra os direitos 
Jonathan Bernardo Menger. Signo ideológico e enunciado na construção e disseminação de fake news: uma possibilidade de análise do fenômeno sob o viés bakhtiniano.

humanos, os nomes, bem como as imagens ${ }^{10}$, estarão apagados, visto que a finalidade do objeto é a análise do discurso em si.

O propósito da investigação, além de comentar e descrever os pressupostos dialógicos apresentados acima, é também o de refletir sobre as especificidades que parecem ser características comuns de "notícias" falsas. A imagem retratada abaixo abordará temática de cunho político. Essa escolha deve-se ao fato de ter ocorrido um grande número de falsas informações disseminadas durante as eleições presidenciais de 2018, no Brasil, e também pelo fato de assuntos sobre política serem uma forte fonte para a disseminação de informações enganosas, segundo pesquisas ${ }^{11}$. Além disso, optar por utilizar uma fake news disseminada em meio virtual deve-se ao fato de a internet ser um dos principais meios de comunicação atual ${ }^{12}$ e, também, uma das maiores plataformas na divulgação de discursos falsos.

Figura 1 - Fake sobre Bolsonaro
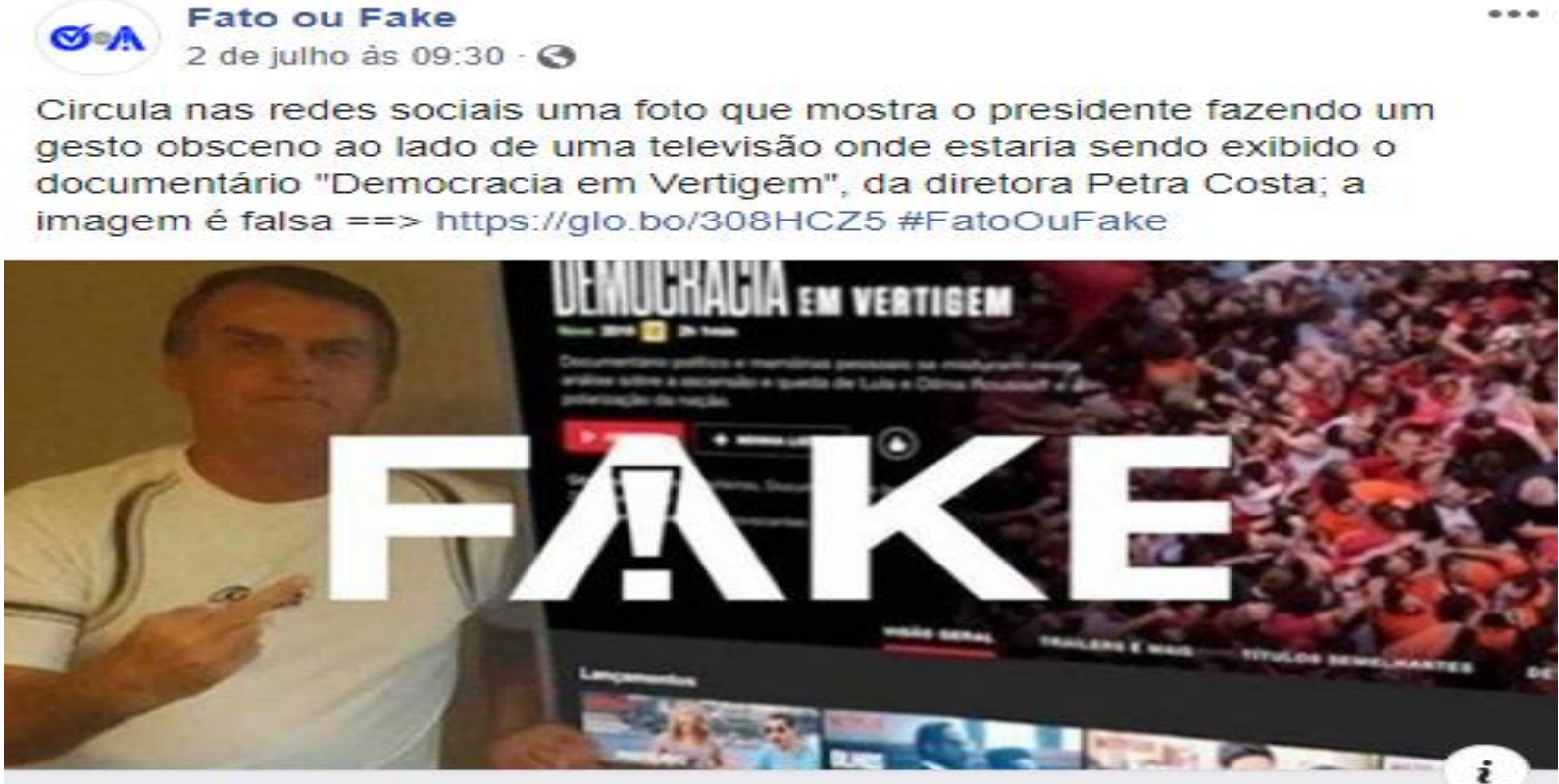

EXTRA.GLOBO.COM

É \#FAKE foto de Bolsonaro fazendo gesto obsceno ao lado de TV que exibe documentário

Fonte: Fato ou Fake - G1 (Facebook) ${ }^{13}$.

\footnotetext{
${ }^{10}$ As imagens são de livre circulação na internet por meio da rede social Facebook.

${ }^{11}$ De acordo com a revista Exame (2018), por exemplo, “A diferença é mais acentuada para notícias políticas $[\ldots] "$.

${ }^{12}$ De acordo com a revista G1 (2014), o segundo meio de comunicação mais usado é a internet.

${ }^{13}$ Consulta realizada em 10 jul. 2019.
} 
Jonathan Bernardo Menger. Signo ideológico e enunciado na construção e disseminação de fake news:

uma possibilidade de análise do fenômeno sob o viés bakhtiniano.

Figura 2 - Comentários a respeito da postagem
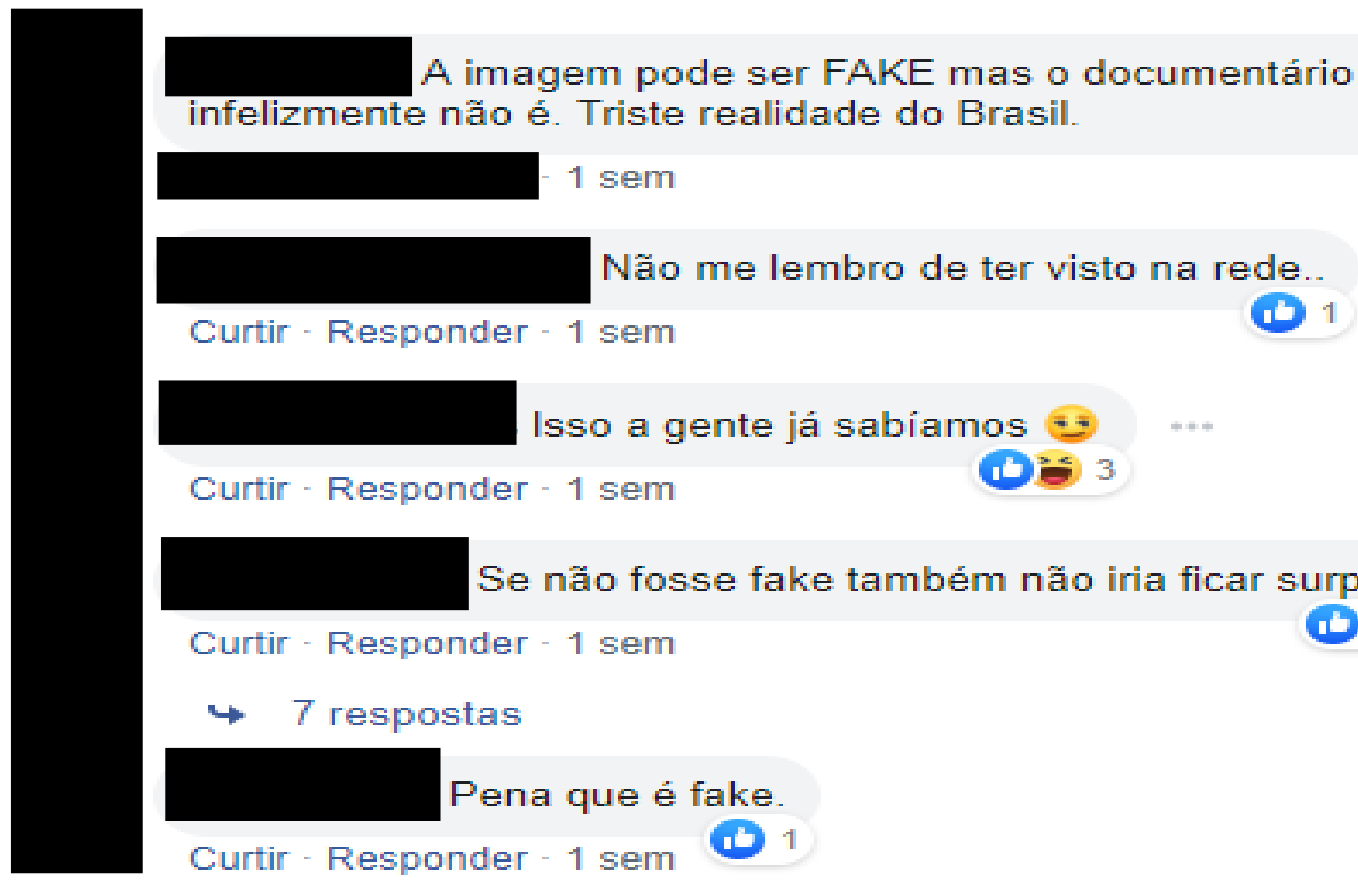

Não me lembro de ter visto na rede.
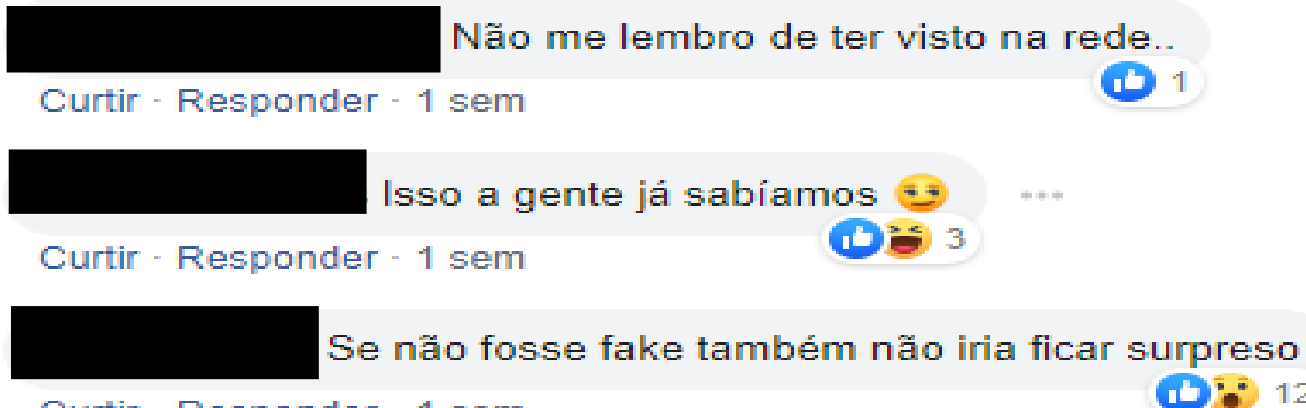

Curtir - Responder - 1 sem

$\rightarrow 7$ respostas

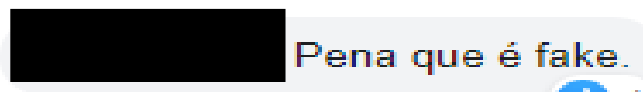

Curtir - Responder - 1 sem
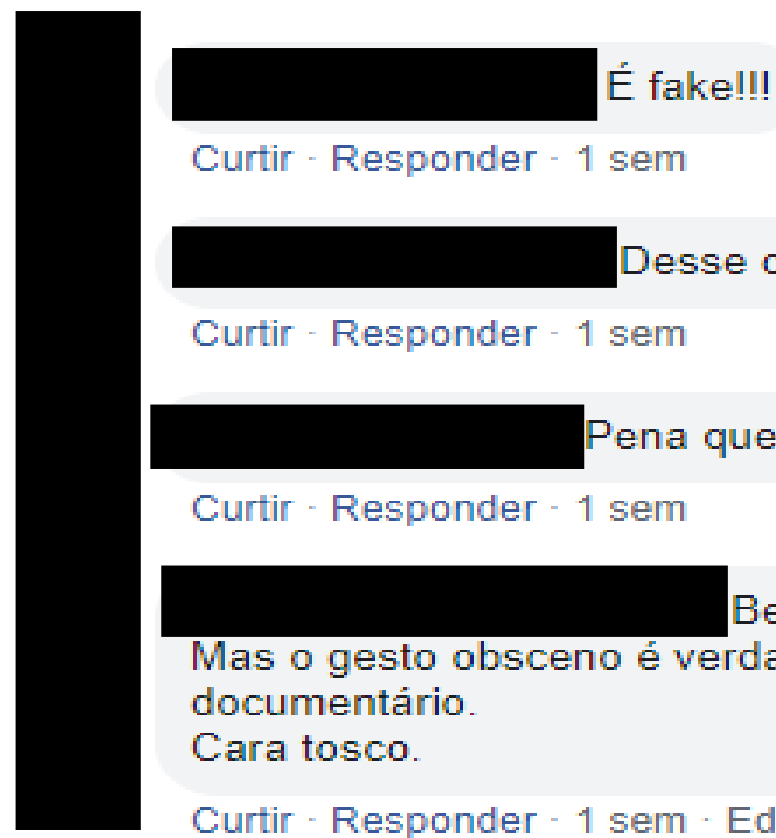

Curtir - Responder - 1 sem

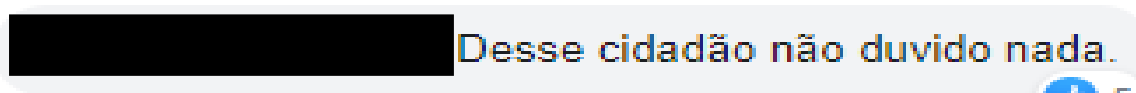

Curtir - Responder - 1 sem

(1) 5

Pena que é fake, deveria ter feito mesmo

Curtir - Responder - 1 sem

Beleza. É fake a imagem da tv.

Mas o gesto obsceno é verdadeiro né. Assim como é verdadeiro o documentário.

Cara tosco.

Curtir-Responder - 1 sem - Editado

Fonte: Fato ou Fake - G1 (Facebook) ${ }^{14}$.

Na Figura 1, é possível observar o atual presidente Jair Bolsonaro fazendo um gesto desrespeitoso com o dedo médio apontado para uma televisão ao seu lado, que, no momento, está apresentando uma imagem do documentário a ser exibido. Segundo pesquisas da página de checagem da G1, essa informação que circula nas redes sociais é falsa.

${ }^{14}$ Consulta realizada em 10 jul. 2019. 
Essa postagem (Figura 1) apresenta duas construções enunciativas: a do texto escrito pela própria página (no início do post e na legenda da foto), e a da imagem falsa, em si. No entanto, sob o viés bakhtiniano, pode-se compreender esse discurso em forma de texto como um todo, que, por construir uma rede única de significações - pois a relação entre todos os signos é capaz de constituir um só sentido -, emancipa-se como um enunciado concreto.

Quanto ao texto que apresenta a imagem falsa, podem-se observar aspectos linguísticos (escritos pelo título do documentário, destacado em branco e em letras maiúsculas, seguido de uma sinopse, não legível) engendrados por um conteúdo extraverbal (a figura do presidente e da imagem da televisão), o qual, em um primeiro instante, parece chamar mais a atenção do leitor. No entanto, essa fake news não é capaz de ser compreendida por si mesma, senão por outros elementos que precisam ser retomados para a sua interpretação, como é o caso dos subentendidos. Nessa ideia, a compreensão só pode ser tida no paralelo entre "[...] uma parte realizada verbalmente e o subentendido" (VOLOCHÍNOV, 2013, p. 79). Sendo assim, o gesto do presidente, denotando uma expressão descontente e desrespeitosa, só é compreendido se o leitor conhecer previamente o assunto abordado pelo documentário - não contemplado na postagem da página. Poder-se-ia dizer que o título, por si só, daria um sentido satisfatório ao contexto, graças à palavra "democracia", bastante utilizada por discursos opostos ao Partido Social Liberal, que enxergavam a derrocada de muitos direitos dos cidadãos brasileiros na vitória de Bolsonaro. Contudo, a relação do conteúdo extraverbal que engendra a situação representada na imagem é importante para a compreensão de um leitor com pouca informação, por exemplo.

Alicerçando-se, então, nos subentendidos, saber-se-á que o documentário aborda a queda da democracia no Brasil nos últimos anos de governo anterior, focando, como personagens principais da tragédia em ascensão, nos ex-presidentes da República Dilma Rousseff e Luiz Inácio Lula da Silva. Bolsonaro, pertencendo ao atual partido governante do país, desde as eleições de 2018, posicionava-se extremamente contrário ao Partido dos Trabalhadores, ao qual pertenciam os ex-governantes, cujos ideais políticos eram bastante divergentes. Tendo-se essa informação metatextual sobre o assunto, é possível constar esse conteúdo como um enunciado concreto, pois permite um reconhecimento do contexto e, por conseguinte, uma compreensão seguida de uma avaliação a respeito do conteúdo. Além disso, pode-se dizer também que a fake news criada se constitui como um signo ideológico, pois apresenta um ponto de vista de seu criador e reflete, inevitavelmente, em outras perspectivas às quais está orientada (como é o caso do post da página e da resposta dos usuários, na Figura 2). 
Observando-se quem, supostamente, construiu essa fake news, pode-se pressupor que o autor se posiciona contra os ideais do atual governante, buscando denegrir a figura do atual presidente. A articulação de duas imagens justapostas uma ao lado da outra (a da televisão e a de Bolsonaro) vai além da simples ideia de representar um objeto e faz recordar a distinção postulada por Bakhtin e seu Círculo sobre signo e sinal: Bolsonaro não só aparece falsamente apontando a TV, como ressignificando-a. Essa ressignificação é mais forte quando atribuída ao criador da fake, que por sua vez revelou a relação entre as duas figuras. Se o leitor, por sua vez, é capaz de fazer associações, as faz porque criou também uma rede de significações.

Outra questão importante de se destacar é a representação da palavra "FAKE" construída pelo grupo da G1 para deflagrar essa "notícia" como falsa. Na imagem, é possível observar o vocábulo justaposto sobre a fake news, em letras garrafais e com um ponto de exclamação completando o desenho de "A". Isso simboliza um posicionamento ideológico da equipe G1 frente àquilo que é falso e vai ao encontro da moral e da ética com a verdade, enfatizando a valoração negativa comumente atribuída às fake news. $\mathrm{O}$ ponto de exclamação serviria como uma espécie de "basta" a possíveis disseminações desse tipo de discurso.

A tese defendida pelo Círculo, de que "cada enunciação está dirigida a um ouvinte" (VOLOCHÍNOV, 2013, p. 163), pode ser observada em três momentos: (1) na construção da fake news; (2) na postagem do grupo de checagem; e (3) nas respostas dos usuários. Na criação da falsa informação, o autor (1) certamente pressupôs um determinado grupo a quem dirigiu seu enunciado - designado por Volochínov (2013, p. 169) como "auditório da enunciação" -, o qual, nesse caso, não está presente, mas sim pressuposto, pois organiza seu discurso com base em seus possíveis ouvintes. Sendo assim, é possível notar duas respostas a essa fake news: a da postagem (2), condenando sua circulação, dizendo que anda sendo disseminada em plataformas virtuais, e a dos usuários da página (3), respondendo, por sua vez, pelo menos a mais de duas orientações - ou seja, não só à fake compartilhada, como também ao grupo de checagem, que tornou pública aquela informação e, indiretamente, a outros usuários que visualizaram, reagiram e/ou responderam em seus comentários.Falas como "Isso a gente já sabíamos", por exemplo, dirige-se tanto ao conteúdo apresentado pela página quanto ao conteúdo transmitido pela falsa informação; "Pena que é fake" demonstra, em sua resposta, tanto uma decepção com o fato apresentado pelo post quanto uma apreciação pela informação enganosa, dizendo que se fosse verdadeira seria útil e agradável; "Se não fosse fake, também não iria ficar surpreso", além de responder ao fato checado e ao conteúdo representado, pressupõe ainda mais sete respostas à sua. Esse fenômeno, instaurado na linguagem, corrobora as palavras do Círculo, uma vez que “[...] todo discurso é dialógico, 
Jonathan Bernardo Menger. Signo ideológico e enunciado na construção e disseminação de fake news: uma possibilidade de análise do fenômeno sob o viés bakhtiniano.

dirigido a outra pessoa, à sua compreensão e à sua efetiva resposta potencial" (VOLOCHÍNOV, 2013, p. 196). Nesse sentido, poder-se-ia ir adiante ao conceber as reações ao post, pois elas também configuram uma resposta à atitude dada. Embora haja apenas 50 comentários de um total de 256 pessoas que reagiram à matéria, não se pode dizer que cerca de duzentos usuários ficaram em silêncio - o que, para Bakhtin, também é uma resposta -, pois suas reações de "curtida", "gargalhada" e "amei", em uma pesquisa mais profunda, evidenciariam igualmente um posicionamento dos agentes interdiscursivos.

Para Bakhtin, os seres sociais, no fenômeno da enunciação, podem, em sua ativaresponsividade, concordar ou discordar de seu interlocutor, demonstrando seus posicionamentos ideológicos. Nessa tensão dialógica, é possível observar nos comentários da figura 2, como, certamente, posiciona-se cada agente interlocutivo em referência a Jair Bolsonaro. Em "Pena que é fake, deveria ter feito mesmo", nota-se uma atitude a favor da postura do presidente, e da mesma forma percebe-se um pesar do usuário em saber que a informação não passa de uma fake news. Ainda é possível dizer que, em se tratando da pósverdade, ele certamente se deixaria se desinformar para compartilhar dessa informação falsa. O comentário "A imagem pode ser fake, mas o documentário infelizmente não é. Triste realidade do Brasil" retira a atenção tanto da TV quanto de Bolsonaro para focalizar o conteúdo exibido pelo filme. Até a segunda oração ${ }^{15}$ desse enunciado concreto, não se poderia afirmar se o usuário foi a favor ou não do documentário, posicionamento visível apenas na terceira oração, em que "Triste realidade do Brasil" denota o pesar do sujeito interdiscursivo ao concordar com o levantamento documentado pela película. Essa divergência de vozes configura a "luta de classes", comentada por Volóchinov (2018), quando diz que "[...] em todo signo ideológico cruzam-se ênfases multidirecionadas" e, por isso, "O signo transformase no palco da luta de classes" (VOLÓCHINOV, 2018, p. 113).

Uma característica bastante possível nas fake news é o fato de elas se travestirem de pequenos recortes da realidade capazes de enganar e confundir o leitor. Certamente, se não fosse o empenho do grupo "Fato ou fake", muitas pessoas se deixariam acreditar pela falsa informação, pois o criador utilizou da postura agressiva de Bolsonaro, que é um fato recorrente e verdadeiro em seus discursos de ódio durante sua função pública, e já foi comprovado igualmente por muitas fontes. Respostas como "Se não fosse fake, também não iria ficar surpreso", "Desse cidadão não duvido nada", “[...] Mas o gesto obsceno é

\footnotetext{
${ }^{15}$ Embora Bakhtin (2018, p. 278) observe a oração como "unidade da língua", de "natureza gramatical", utilizou-se no texto essa expressão apenas com a finalidade de fazer um recorte para o que se pretende explicar na análise.
} 
Jonathan Bernardo Menger. Signo ideológico e enunciado na construção e disseminação de fake news: uma possibilidade de análise do fenômeno sob o viés bakhtiniano.

verdadeiro, né $[\ldots]$ " elucidam sua postura e fazem o leitor acreditar numa possibilidade de ter sido verdadeira essa informação. Dessa forma, pareceu ser conveniente ao criador utilizar de uma verdade para construir uma informação enganosa. É difícil precisar o posicionamento político de quem criou essa fake news, uma vez que há fronteiras bem estabelecidas na análise do discurso entre o que se pode observar do dito e sua real intenção. Se seu objetivo foi denegrir a imagem do presidente, seria possível pensar seu posicionamento como sendo pertinente ao que, atualmente, se concretiza em variados discursos como "esquerda partidária". Ao contrário, se intencionou deturpar o documentário "Ditadura em vertigem", seria possível classificar sua posição como pertencente à extrema direita.

Outra característica bastante predominante na construção de fake news é o apelo ao uso de outros recursos que ultrapassam o texto verbal escrito, contribuindo para a construção de sentidos na compreensão do enunciado como um todo. Isso faz repensar o sentido literal de "notícia", uma vez que, às vezes, as informações enganosas em nada se assemelham a esse gênero discursivo. Nesse aspecto, constata-se nessa página da G1 um grande número de postagens fakes construídas em áudio, vídeos e fotos. Quando em imagens, costumam apresentar conteúdos escandalosos, apelando para o exagero, o que pode ser apreciado também como o tom valorativo dado a determinada relação sígnica. Volochínov (2013, p. 181) explica que isso se deve "à orientação social", a qual, por sua vez, "determina a entonação". Exemplo disso, na fake em questão, é a pose de Jair Bolsonaro, coisa censurável vindo de um presidente da república. Além disso, algo importante de se observar é sua plataforma discursiva de repercussão: "Circula nas redes sociais [...]" não deixa de ser um eco de discursos já concretizados em pesquisas anteriores, evidenciando a internet como um meio eloquente na disseminação de falsas informações. De forma igualmente instigante, grande número de postagens dessa página de checagem traz no corpo de seu texto que as fake news deflagradas circularam em redes sociais, a exemplo de plataformas como Whatsapp e Facebook. Há estudos dissertando a respeito desses meios. Segundo a revista Exame (2018), por exemplo, as notícias falsas costumam ser divulgadas mais rápido que as verdadeiras, e majoritariamente pela internet. O comentário "Não me lembro de ter visto na rede" pode servir, grosso modo, de exemplificação para se refletir o quão comum é o fato de as pessoas estarem incessantemente conectada às redes virtuais e por lá se informarem.

Como já foi dito, não é possível delimitar a real intenção psíquica no ato enunciativo. Entretanto, é admissível pressupor, no discurso, uma possível observação sobre o posicionamento do grupo G1 em ter deflagrado uma fake news contra Bolsonaro. Isso porque, nas postagens dessa página, é comum um grande número de "notícias" falsas criadas a favor 
do presidente, tanto antes quanto depois de sua candidatura, transparecendo, talvez, aos seguidores como um ato de conspiração da Rede Globo contra o governante. Pode-se dizer que, embora o objetivo mor do grupo de checagem seja o de lidar, moral e eticamente, com a verdade, a empresa de checagem talvez quisesse transparecer-se de forma levemente imparcial ao apresentar a circulação de uma fake news que denegria a imagem do presidente, ao qual tanto já atribuiu críticas. Isso pode lhes garantir um status de legitimidade. Uma possível exemplificação disso pode ser notada na reação de agrado dos seguidores, tanto naqueles que dizem realmente ter sido fake, quanto naqueles que só reagiram com "curtidas" e/ou preferiram não se manifestar verbalmente. Em outras postagens, quando direta ou indiretamente critica a figura pública que fora eleita por mentiras, a página é fortemente condenada por usuários da oposição, com expressões como "Globo lixo", "A própria Globo produz fake news". Dessa forma, foi possível observar uma atitude de quebra da G1, em uma matéria que, diferentemente de muitas outras vezes, mostra-se defendendo o atual presidente. Vale lembrar que, de 123 fake news produzidas durante o período eleitoral, 109 mostravam conteúdos a favor do candidato vencedor das eleições presidenciais de 2018, de acordo com levantamento realizado pelas empresas de fact-checking Lupa e Aos Fatos (MACEDO, 2018). Os efeitos de pós-verdade são sempre perigosos, ainda mais quando a viralização de falsas informações parte de figuras políticas.

\section{Considerações finais}

Usufruir de tópicos da teoria bakhtiniana para a discussão das fakenews se justifica pelo fato de essa problemática consolidar-se como um fenômeno próprio da linguagem. Dessa maneira, tanto pesquisas que discorrem sobre as falsas informações quanto textos que abordam os estudos do Círculo encontram raízes na essência da língua in actu, sob uma proposta filosófica e sociológica de se conceber o discurso, concreto, heterogêneo e ininterrupto na vida interdiscursiva.

As fake news não serviriam de objeto para quaisquer tipos de análise e questionamentos se não fosse por um fenômeno que lhe é muito próximo: a pós-verdade. A reação e o posicionamento dos seres interdiscursivos, perante os demais fenômenos da vida cotidiana, são cruciais e dizem muito sobre o bem-estar social. Isso porque os discursos, sempre carregados de tensões, são as válvulas que impulsionam as ações humanas. Nesse sentido, o impacto causado pelas fake news em nível coletivo, e não apenas individual - como 
foi o caso do movimento antivacina, exemplificado no texto - parece encontrar em Bakhtin um solo fértil na percepção e apreciação da linguagem como construto político, social e ideológico.

As falsas informações, como analisaram alguns autores citados no decorrer deste texto, sempre existiram, porque fazem parte da híbrida, heterogênea e instável linguagem humana. Sendo um fato, elas ganham mais influência nos dias de hoje, ao se pensar no advento da tecnologia - o que não deixa de justificar também a escolha do corpus de análise deste artigo. As maneiras de se transmitir mentiras se tornaram maiores, em se pensando nas diversas plataformas de comunicação social capazes de reunir milhares de pessoas discutindo sobre eventos diversos. Nesse ponto, faz-se importante também um olhar reflexivo sobre a manifestação das fake news, uma vez que a mentira não só se traveste da verdade como é capaz de adquirir roupagens distintas em sua disseminação: uma propaganda, um comercial, um simples vídeo etc., não têm caráter constitutivo de notícia, com manchete, linha fina, tampouco segue um sistema piramidal no objetivo de informar; no entanto, não deixam de ser enganosas. Essa observação faz recordaras palavras de Bakhtin (2018), quando disserta a respeito da transgressão dos gêneros. Embora, literalmente, as fake news sejam traduzidas como “"notícias' falsas”, elas não mantêm necessariamente forma e conteúdo semelhante ao gênero discursivo notícia. Por serem mais plásticas, isto é, por se adaptarem a diversas formas, poderiam ainda ser configuradas como um tipo de enunciado relativamente estável à parte, devido às suas peculiaridades fenomenológicas. Uma visão aprofundada desse aspecto poderia contribuir também para o esclarecimento da mentira e sua respectiva prevenção.

Além disso, há poucos trabalhos publicados a respeito dessa temática. Um olhar na área da filosofia da linguagem, como propõem os textos referentes ao Círculo, por exemplo, pode ser útil para impulsionar o interesse pelo tema e a respectiva escrita em outras áreas do conhecimento. Urge a necessidade de se discutir e estudar esse fenômeno, que sempre se fará presente e, por isso, requer a ciência como maneira de precaução e combate.

\section{Referências}

BAKHTIN, Mikhail. Estética da criação verbal. Tradução Paulo Bezerra. São Paulo: WMF Martins Fontes, 2018.

BAKHTIN, Mikhail. Os gêneros do discurso. In: Estética da criação verbal. Tradução Paulo Bezerra. São Paulo: WMF Martins Fontes, 2018, p. 261-306. 
BRAIT, Beth; MELO, Rosineide. Enunciado/enunciado concreto/enunciação. In: BRAIT, Beth (Org.): Bakhtin: conceitos-chave. São Paulo: Contexto, 2017, p. 61-79.

CAMPOS, Lorraine Vilela. $\mathrm{O}$ que são Fake News? Disponível em: <https://brasilescola.uol.com.br/curiosidades/o-que-sao-fake-news.htm>. Acesso em: 8 maio 2019.

CARTA CAPITAL. Pós-verdade: o conceito político da moda é equivocado. Disponível em: $<$ https://www.cartacapital.com.br/blogs/vanguardas-do-conhecimento/o-conceito-politico-damoda-pos-verdade-e-equivocado/>. Acesso em: 9 maio 2019.

CARVALHO, M. F. C.; MATHEUS, C. A. Fake news e desinformação no meio digital: análise da produção científica sobre o tema na área de ciência da informação. UFMG, Belo Horizonte, p. 1-13, 2018.

D’ANCONA, Matthew. Pós-verdade: a nova guerra contra os fatos em tempos de fake news. Barueria: Faro Editorial, 2018.

EXAME. Fake news circulam mais rápido do que notícias reais, diz estudo. Disponível em: $<$ https://exame.abril.com.br/tecnologia/fake-news-circulam-mais-rapido-do-noticias-reais-dizestudo/>. Acesso em: 10 jul. 2019.

FALLON, Claire. De onde vem o termo fake news? Da década de 1890, ao que tudo indica. Disponível em: <https://www.huffpostbrasil.com/2017/04/05/de-ondevem-o-termo-fakenews-da-decada-de-1890-ao-que-tudo_a_22027223/>. Acesso em: 18 nov. 2018.

FERRARI, Pollyana. Como sair das bolhas. São Paulo: Armazém da Cultura, 2018.

G1. Segundo meio de comunicação mais usado é a internet, aponta pesquisa. Disponível em: <http://g1.globo.com/economia/midia-e-marketing/noticia/2014/03/segundo-meio-decomunicacao-mais-usado-e-internet-aponta-pesquisa.html>. Acesso em: 27 maio 2018.

HARARI, Yuval Noah. Sapiens: uma breve história da humanidade. Porto Alegre: L\&PM, 2017.

MACEDO, Isabella. Das 123 fake news encontradas por agências de checagem, 104 beneficiaram Bolsonaro. Disponível em: <https://congressoemfoco.uol.com.br/eleicoes/das123-fake-news-encontradas-por-agencias-de-checagem-104-beneficiaram-bolsonaro/> .

Acesso em: 9 maio 2019.

MIOTELLO, Valdemir. Ideologia. In: BRAIT, Beth (Org.): Bakhtin: Conceitos-chave. São Paulo, Contexto: 2017. p. 167-177.

VOLÓCHINOV, Valentin Nikolaevich (BAKHTIN, Mikhail). Marxismo e filosofia da linguagem: problemas fundamentais do método sociológico na ciência da linguagem. Tradução Sheila Grillo e Ekaterina Vólkova Américo. São Paulo: Editora 34, 2018.

VOLOCHÍNOV, Valentin Nikolaevich. A construção da enunciação e outros ensaios. Organização, tradução e notas João Wanderley Geraldi. São Carlos: Pedro \& João Editores, 2013. 
VOLOCHÍNOV, Valentin Nikolaevich. Discurso na vida e discurso na arte: sobre poética sociológica. Disponível em: <https://kupdf.net/queue/m-bakhtin-discurso-na-vida-discursona-arte_59d322b708bbc58a5a6871e3_pdf?queue_id=-

$1 \& x=1559226341 \& z=M T Y 4 L j E 4 M S 4 z N y 4 y M D Y=>$. Acesso em: 30 maio 2019.

Recebido em: 21 de agosto de 2019

Aceito em: 21 de novembro de 2019 